\title{
Existence and Uniqueness of Best Proximity Points for Generalized Almost Contractions
}

\author{
Chirasak Mongkolkeha, ${ }^{1}$ Chayut Kongban, ${ }^{2}$ and Poom Kumam ${ }^{2}$ \\ ${ }^{1}$ Department of Mathematics, Faculty of Liberal Arts and Science, Kasetsart University, \\ Kamphaeng Saen Campus, Nakhon Pathom 73140, Thailand \\ ${ }^{2}$ Department of Mathematics, Faculty of Science, King Mongkut's University of Technology Thonburi (KMUTT), \\ Bangkok 10140, Thailand
}

Correspondence should be addressed to Poom Kumam; poom.kum@kmutt.ac.th

Received 5 August 2013; Revised 19 November 2013; Accepted 26 December 2013; Published 16 March 2014

Academic Editor: Adrian Petrusel

Copyright (C) 2014 Chirasak Mongkolkeha et al. This is an open access article distributed under the Creative Commons Attribution License, which permits unrestricted use, distribution, and reproduction in any medium, provided the original work is properly cited.

The purpose of this paper is to elicit some interesting extensions of generalized almost contraction mappings to the case of nonself-mappings with $\alpha$-proximal admissible and prove best proximity point theorems for this classes. Moreover, we also give some examples and applications to support our main results.

\section{Introduction}

Many problems can be formulated as equations of the form $T x=x$, where $T$ is a self-mapping with some suitable domains. From the fact that fixed point theory plays an important role in furnishing a uniform treatment to solve various equations of the form $T x=x$ However, in the case that $T$ is non-self-mapping, the aforementioned equation does not necessarily have a fixed point. In such case, it is worthy to determine an approximate solution $x$ such that the error $d(x, T x)$ is minimum. This is the idea behind best approximation theory. $A$ classical best approximation theorem was introduced by Fan [1]; that is, if $A$ is a nonempty compact convex subset of a Hausdorff locally convex topological vector space $B$ and $T: A \rightarrow B$ is a continuous mapping, then there exists an element $x \in A$ such that $d(x, T x)=$ $d(T x, A)$. Afterward, several authors, including Prolla [2], Reich [3], and Sehgal and Singh [4, 5], have derived extensions of Fan's Theorem in many directions. Moreover, for a detailed account of global optimization and the existence of a best proximity point, one can refer to [5-15]. In 2013, Samet [16] studied the existence and uniqueness of best proximity points for almost $(\varphi, \theta)$-contractive mappings in complete metric spaces. Recently, Jleli et al. [17] introduced a new class of non-self-contractive mappings with generalization of $\alpha$ proximal admissible defined by Samet et al. [18] which is called $\alpha-\psi$-proximal contractive type mappings and proved existence and uniqueness of best proximity points.

Motivated from the above results, we will study the best proximity point theorem for new classes as generalized almost contraction in metric spaces by using the $\alpha$-proximal admissible of Jleli et al. [17]. Also, we give some illustrative examples and applications to support our main results.

\section{Preliminaries}

Let $A$ and $B$ be nonempty subsets of a metric space $(X, d)$; we recall the following notations and notions that will be used in what follows:

$$
\begin{aligned}
& d(A, B):=\inf \{d(x, y): x \in A \text { and } y \in B\}, \\
& A_{0}:=\{x \in A: d(x, y)=d(A, B) \text { for some } y \in B\}, \\
& B_{0}:=\{y \in B: d(x, y)=d(A, B) \text { for some } x \in A\} .
\end{aligned}
$$

If $A \cap B \neq \emptyset$, then $A_{0}$ and $B_{0}$ are nonempty. Further, it is interesting to notice that $A_{0}$ and $B_{0}$ are contained in the boundaries of $A$ and $B$, respectively, provided $A$ and $B$ are 
closed subsets of a normed linear space such that $d(A, B)>0$ (see [19]).

Definition 1. A point $x \in A$ is said to be a best proximity point of the mapping $S: A \rightarrow B$ if it satisfies the following condition:

$$
d(x, S x)=d(A, B) .
$$

It can be observed that a best proximity reduces to a fixed point if the underlying mapping is a self-mapping.

Definition 2 (see [13]). Let $(A, B)$ be a pair of nonempty subsets of $X$ with $A_{0} \neq \emptyset$. Then the pair $(A, B)$ is said to have the $P$-propertyif and only if

$$
\left\{\begin{array}{l}
d\left(x_{1}, y_{1}\right)=d(A, B) \\
d\left(x_{2}, y_{2}\right)=d(A, B)
\end{array} \Longrightarrow d\left(x_{1}, x_{2}\right)=\left(y_{1}, y_{2}\right)\right.
$$

where $x_{1}, x_{2} \in A_{0}$ and $y_{1}, y_{2} \in B_{0}$.

It is easy to see that, for any nonempty subset $A$ of $X$, the pair $(A, A)$ has the $P$-property.

Example 3 (see [13]). Let $A, B$ be two nonempty closed convex subsets of a Hilbert space $X$. Then $(A, B)$ satisfies the P-property.

Example 4 (see [20]). Let $A, B$ be two nonempty, bounded, closed, and convex subsets of a uniformly convex Banach space $X$. Then $(A, B)$ has the $P$-property.

Example 5 (see [20]). Let $X=R^{2}$ with the metric defined by

$$
d\left(\left(x_{1}, y_{1}\right),\left(x_{2}, y_{2}\right)\right)=\max \left\{\left|x_{1}-y_{1}\right|,\left|x_{2}-y_{2}\right|\right\}
$$

Let $A:=\{(x, 0):-1 \leq x \leq 1\}$ and $B:=\{(0, y):-1 \leq y \leq 1\}$. Then $(A, B)$ satisfies the $P$-property.

Definition 6 (see [18]). A self-mapping $T: X \rightarrow X$ is said to be $\alpha$-admissible, where $\alpha: X \times X \rightarrow[0, \infty)$, if

$$
x, y \in X, \quad \alpha(x, y) \geq 1 \Longrightarrow \alpha(T x, T y) \geq 1
$$

Definition 7 (see [17]). Let $T: A \rightarrow B$ and $\alpha: A \times A \rightarrow$ $[0, \infty)$. One says that $T$ is $\alpha$-proximal admissible, if

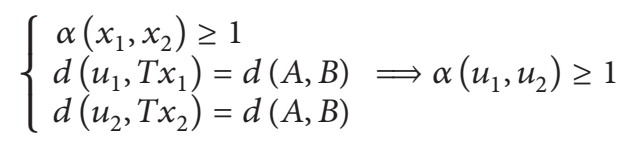

for all $x_{1}, x_{2}, u_{1}, u_{2} \in A$.

Clearly, for self-mapping, $T$ being $\alpha$-proximal admissible implies that $T$ is $\alpha$-admissible.

Definition 8 . One says the function $\varphi:[0, \infty) \rightarrow[0, \infty)$ is a (c)-comparison function if and only if the following conditions hold:
$\left(\Phi_{1}\right) \varphi$ is a nondecreasing function,

$\left(\Phi_{2}\right)$ for any $t>0, \sum_{n=1}^{\infty} \varphi^{n}(t)$ is a convergent series.

One denotes the set of (c)-comparison function by $\Psi$.

It is easily proved that if $\varphi$ is a (c)-comparison function, then $\varphi(t)<t$ for all $t>0$.

Definition 9 (see [16]). Let $\theta:[0, \infty)^{4} \rightarrow[0, \infty)$ satisfy the following conditions:

(1) $\theta$ is continuous,

(2) $\theta(a, b, c, d)=0$ if and only if the product $a b c d=0$.

One denotes the class of function $\theta$ by $\Theta$.

Example 10 (see [16]). The following functions belong to $\Theta$ :
(1) $\theta\left(t_{1}, t_{2}, t_{3}, t_{4}\right)=\tau \min \left\{t_{1}, t_{2}, t_{3}, t_{4}\right\}, \tau>0$;
(2) $\theta\left(t_{1}, t_{2}, t_{3}, t_{4}\right)=\tau \ln \left(1+t_{1} t_{2} t_{3} t_{4}\right), \tau>0$;
(3) $\theta\left(t_{1}, t_{2}, t_{3}, t_{4}\right)=\tau t_{1} t_{2} t_{3} t_{4}, \tau>0$.

\section{The Existence and Uniqueness of Best Proximity Points}

In this section, we introduce the new class of the generalized Banach contraction for non-self-mappings so-called generalized almost $(\varphi, \theta)_{\alpha}$ contraction and we also study the best proximity theorems for these classes. First, we recall the notion of $(\varphi, \theta)$ contraction defined by Samet [16] as follows.

Definition 11 (see [16]). Let $A$ and $B$ be nonempty subsets of metric space $X$. A mapping $T: A \rightarrow B$ is said to be an almost $(\varphi, \theta)$ contraction if and only if there exist $\varphi \in \Psi$ and $\theta \in \Theta$ such that, for all $x, y \in A$,

$$
\begin{gathered}
d(T x, T y) \leq \varphi(d(x, y)) \\
+\theta(d(y, T x) \\
\quad-d(A, B), d(x, T y)-d(A, B), d(x, T x) \\
-d(A, B), d(y, T y)-d(A, B))
\end{gathered}
$$

\subsection{The Existence}

Definition 12. Let $A$ and $B$ be nonempty subsets of metric space $X$. A mapping $T: A \rightarrow B$ is said to be a generalized almost $(\varphi, \theta)_{\alpha}$ contraction if and only if

$$
\begin{aligned}
\alpha(x, y) d(T x, T y) \\
\leq \varphi(M(x, y)) \\
+\theta(d(y, T x)-d(A, B), d(x, T y) \\
\quad-d(A, B), d(x, T x)-d(A, B), d(y, T y) \\
-d(A, B)),
\end{aligned}
$$


for all $x, y \in A$, where $\alpha: A \times A \rightarrow[0, \infty), \varphi \in \Psi \theta \in$ $\Theta$, and

$$
\begin{aligned}
& M(x, y) \\
& =\max \{d(x, y), d(x, T x)-d(A, B), d(y, T y) \\
& \left.\quad-d(A, B), \frac{1}{2}[d(x, T y)+d(y, T x)]-d(A, B)\right\} .
\end{aligned}
$$

Clearly, if we take $\alpha(x, y)=1$ for all $x, y \in A$ and $M(x, y)=d(x, y)$, the generalized almost $(\varphi, \theta)_{\alpha}$ contraction reduces to almost $(\varphi, \theta)$ contraction.

Theorem 13. Let $A$ and $B$ be nonempty closed subsets of $a$ complete metric space $X$ such that $A_{0}$ is nonempty and the pair $(A, B)$ has the P-property. Let $T: A \rightarrow B$ satisfy the following conditions:

(a) $T$ are $\alpha$-proximal admissible and generalized almost $(\varphi, \theta)_{\alpha}$-contraction;

(b) $T$ is continuous;

(c) there exist elements $x_{0}$ and $x_{1}$ in $A_{0}$ such that $d\left(x_{1}, T x_{0}\right)=d(A, B)$ and $\alpha\left(x_{0}, x_{1}\right) \geq 1$;

(d) $T\left(A_{0}\right) \subseteq B_{0}$.

Then there exists an element $x \in A$ such that

$$
d(x, T x)=d(A, B) .
$$

Moreover, for any fixed $x_{0} \in A_{0}$, the sequence $\left\{x_{n}\right\}$, defined by

$$
d\left(x_{n+1}, T x_{n}\right)=d(A, B),
$$

converges to the element $x$.

Proof. By the hypothesis (c), there exist $x_{0}$ and $x_{1}$ in $A_{0}$ such that

$$
d\left(x_{1}, T x_{0}\right)=d(A, B), \quad \alpha\left(x_{0}, x_{1}\right) \geq 1 .
$$

From the fact that $T\left(A_{0}\right) \subseteq B_{0}$, there exists an element $x_{2} \in$ $A_{0}$ such that

$$
d\left(x_{2}, T x_{1}\right)=d(A, B) .
$$

By (12), (13), and the $\alpha$-proximal admissible, we get

$$
\alpha\left(x_{1}, x_{2}\right) \geq 1 \text {. }
$$

Since $T\left(A_{0}\right) \subseteq B_{0}$, we can find an element $x_{3} \in A_{0}$ such that

$$
d\left(x_{3}, T x_{2}\right)=d(A, B) .
$$

Again, by (13), (15), and the $\alpha$-proximal admissible, we have

$$
\alpha\left(x_{2}, x_{3}\right) \geq 1 \text {. }
$$

By similar fashion, we can find $x_{n}$ in $A_{0}$. Having chosen $x_{n}$, one can determine an element $x_{n+1} \in A_{0}$ such that

$$
d\left(x_{n+1}, T x_{n}\right)=d(A, B), \quad \alpha\left(x_{n}, x_{n+1}\right) \geq 1 .
$$

In view of the fact that the pair $(A, B)$ has $P$-property and generalized almost $(\varphi, \theta)_{\alpha}$-contraction of $T$, we have

$$
\begin{aligned}
d\left(x_{1}, x_{2}\right) & \\
= & d\left(T x_{0}, T x_{1}\right) \\
\leq & \alpha\left(x_{0}, x_{1}\right) d\left(T x_{0}, T x_{1}\right) \\
\leq & \varphi\left(M\left(x_{0}, x_{1}\right)\right) \\
& +\theta\left(d\left(x_{1}, T x_{0}\right)-d(A, B), d\left(x_{0}, T x_{1}\right)-d(A, B),\right. \\
& \left.\quad d\left(x_{0}, T x_{0}\right)-d(A, B), d\left(x_{1}, T x_{1}\right)-d(A, B)\right) \\
= & \varphi\left(M\left(x_{0}, x_{1}\right)\right) \\
& +\theta\left(0, d\left(x_{0}, T x_{1}\right)-d(A, B), d\left(x_{0}, T x_{0}\right)\right. \\
& \left.\quad-d(A, B), d\left(x_{1}, T x_{1}\right)-d(A, B)\right) \\
= & \varphi\left(M\left(x_{0}, x_{1}\right)\right) .
\end{aligned}
$$

Since

$$
\begin{aligned}
& M\left(x_{0}, x_{1}\right) \\
& =\max \left\{d\left(x_{0}, x_{1}\right), d\left(x_{0}, T x_{0}\right)-d(A, B), d\left(x_{1}, T x_{1}\right)\right. \\
& -d(A, B), \frac{1}{2}\left[d\left(x_{0}, T x_{1}\right)+d\left(x_{1}, T x_{0}\right)\right] \\
& -d(A, B)\} \\
& \leq \max \left\{d\left(x_{0}, x_{1}\right), d\left(x_{0}, x_{1}\right)+d\left(x_{1}, T x_{0}\right)\right. \\
& -d(A, B), d\left(x_{1}, x_{2}\right)+d\left(x_{2}, T x_{1}\right) \\
& -d(A, B), \frac{1}{2}\left[d\left(x_{0}, x_{1}\right)+d\left(x_{1}, x_{2}\right)\right. \\
& \left.+d\left(x_{2}, T x_{1}\right)+d(A, B)\right] \\
& -d(A, B)\} \\
& =\max \left\{d\left(x_{0}, x_{1}\right), d\left(x_{1}, x_{2}\right)\right. \text {, } \\
& \frac{1}{2}\left[d\left(x_{0}, x_{1}\right)+d\left(x_{1}, x_{2}\right)+d(A, B)+d(A, B)\right] \\
& -d(A, B)\} \\
& =\max \left\{d\left(x_{0}, x_{1}\right), d\left(x_{1}, x_{2}\right), \frac{1}{2}\left[d\left(x_{0}, x_{1}\right)+d\left(x_{1}, x_{2}\right)\right]\right\} \\
& =\max \left\{d\left(x_{0}, x_{1}\right), d\left(x_{1}, x_{2}\right)\right\} \text {. }
\end{aligned}
$$

By (18) and (19), we get

$$
d\left(x_{1}, x_{2}\right) \leq \varphi\left(\max \left\{d\left(x_{0}, x_{1}\right), d\left(x_{1}, x_{2}\right)\right\}\right) .
$$


If there exists $n_{0} \in \mathbb{N} \cup\{0\}$ such that $x_{n_{0}+1}=x_{n_{0}}$, by (17), we obtain the best proximity point. Suppose that $x_{n+1} \neq x_{n}$ for all $n \in \mathbb{N} \cup\{0\}$; then $d\left(x_{n}, x_{n+1}\right)>0$ for all $n \in \mathbb{N} \cup\{0\}$. If $\max \left\{d\left(x_{0}, x_{1}\right), d\left(x_{1}, x_{2}\right)\right\}=d\left(x_{1}, x_{2}\right)$, by the property $\varphi(t)<$ $t$ for all $t>0$, we get

$$
d\left(x_{1}, x_{2}\right) \leq \varphi\left(\max \left\{d\left(x_{0}, x_{1}\right), d\left(x_{1}, x_{2}\right)\right\}\right)<d\left(x_{1}, x_{2}\right),
$$

which is a contradiction and hence $\max \left\{d\left(x_{0}, x_{1}\right), d\left(x_{1}, x_{2}\right)\right\}$ $=d\left(x_{0}, x_{1}\right)$. That is,

$$
d\left(x_{1}, x_{2}\right) \leq \varphi\left(d\left(x_{0}, x_{1}\right)\right) .
$$

Again, since the pair $(A, B)$ has $P$-property, is $\alpha$-proximal admissible, and generalized almost $(\varphi, \theta)_{\alpha}$-contraction of $T$, we have

$$
\begin{aligned}
d\left(x_{2}, x_{3}\right) & \\
= & d\left(T x_{1}, T x_{2}\right) \\
\leq & \alpha\left(x_{1}, x_{2}\right) d\left(T x_{1}, T x_{2}\right) \\
\leq & \varphi\left(M\left(x_{1}, x_{2}\right)\right) \\
& +\theta\left(d\left(x_{2}, T x_{1}\right)-d(A, B), d\left(x_{1}, T x_{2}\right)-d(A, B),\right. \\
& \left.\quad d\left(x_{1}, T x_{1}\right)-d(A, B), d\left(x_{2}, T x_{2}\right)-d(A, B)\right) \\
= & \varphi\left(M\left(x_{1}, x_{2}\right)\right) \\
& +\theta\left(0, d\left(x_{1}, T x_{2}\right)-d(A, B), d\left(x_{1}, T x_{1}\right)-d(A, B),\right. \\
& \left.\quad d\left(x_{2}, T x_{2}\right)-d(A, B)\right) \\
= & \varphi\left(M\left(x_{1}, x_{2}\right)\right)
\end{aligned}
$$

and since

$$
\begin{aligned}
& M\left(x_{1}, x_{2}\right) \\
& =\max \left\{d\left(x_{1}, x_{2}\right), d\left(x_{1}, T x_{1}\right)-d(A, B), d\left(x_{2}, T x_{2}\right)\right. \\
& -d(A, B), \frac{1}{2}\left[d\left(x_{1}, T x_{2}\right)+d\left(x_{2}, T x_{1}\right)\right] \\
& -d(A, B)\} \\
& \leq \max \left\{d\left(x_{1}, x_{2}\right), d\left(x_{1}, x_{2}\right)+d\left(x_{2}, T x_{1}\right)-d(A, B),\right. \\
& \quad d\left(x_{2}, x_{3}\right)+d\left(x_{3}, T x_{2}\right)-d(A, B),
\end{aligned}
$$

$$
\begin{gathered}
\frac{1}{2}\left[d\left(x_{1}, x_{2}\right)+d\left(x_{2}, x_{3}\right)\right. \\
\left.+d\left(x_{3}, T x_{2}\right)+d(A, B)\right] \\
-d(A, B)\} \\
=\max \left\{d\left(x_{1}, x_{2}\right), d\left(x_{2}, x_{3}\right),\right. \\
\frac{1}{2}\left[d\left(x_{1}, x_{2}\right)+d\left(x_{2}, x_{3}\right)+d(A, B)+d(A, B)\right] \\
-d(A, B)\} \\
=\max \left\{d\left(x_{1}, x_{2}\right), d\left(x_{2}, x_{3}\right),\right. \\
\left.\frac{1}{2}\left[d\left(x_{1}, x_{2}\right)+d\left(x_{2}, x_{3}\right)\right]\right\} \\
=\max \left\{d\left(x_{1}, x_{2}\right), d\left(x_{2}, x_{3}\right)\right\} .
\end{gathered}
$$

By (23) and (24), we get

$$
d\left(x_{2}, x_{3}\right) \leq \varphi\left(\max \left\{d\left(x_{1}, x_{2}\right), d\left(x_{2}, x_{3}\right)\right\}\right) .
$$

By similar argument as above, we can conclude that $\max \left\{d\left(x_{1}, x_{2}\right), d\left(x_{2}, x_{3}\right)\right\}=d\left(x_{1}, x_{2}\right)$ and thus

$$
d\left(x_{2}, x_{3}\right) \leq \varphi\left(d\left(x_{1}, x_{2}\right)\right) .
$$

Using (22) and (26) and the nondecreasing of $\varphi$, we get

$$
d\left(x_{2}, x_{3}\right) \leq \varphi^{2}\left(d\left(x_{0}, x_{1}\right)\right) .
$$

Continuing this process, by induction we have that

$$
d\left(x_{n}, x_{n+1}\right) \leq \varphi^{n}\left(d\left(x_{0}, x_{1}\right)\right)
$$

for all $n \in \mathbb{N} \cup\{0\}$. Fix $\varepsilon>0$ and let $h=h(\varepsilon)$ be a positive integer such that

$$
\sum_{n \geq h} \varphi^{n}\left(d\left(x_{0}, x_{1}\right)\right)<\varepsilon
$$

Let $m>n>h$; using the triangular inequality, (28) and (29), we obtain

$$
\begin{aligned}
d\left(x_{n}, x_{m}\right) & \leq \sum_{k=n}^{m-1} d\left(x_{k}, x_{k+1}\right) \\
& \leq \sum_{k=n}^{m-1} \varphi^{k}\left(d\left(x_{0}, x_{1}\right)\right) \leq \sum_{n \geq h} \varphi^{n}\left(d\left(x_{0}, x_{1}\right)\right)<\varepsilon .
\end{aligned}
$$

This shows that $\left\{x_{n}\right\}$ is a Cauchy sequence. Since $A$ is a closed subset of complete metric spaces $X$, then there exists $x \in A$ such that

$$
\lim _{n \rightarrow \infty} d\left(x_{n}, x\right)=0
$$


By (17), (31), and the continuity of $T$, we get

$$
d(x, T x)=\lim _{n \rightarrow \infty} d\left(x_{n+1}, T x_{n}\right)=d(A, B)
$$

and the proof is complete.

Next, we remove condition $T$ is continuous in Theorem 13, by assuming the following condition which was defined by Jleli et al. [17] for proving the new best proximity point theorem.

(H) If $\left\{x_{n}\right\}$ is a sequence in $A$ such that $\alpha\left(x_{n}, x_{n+1}\right) \geq 1$ for all $n$ and $x_{n} \rightarrow x$ for some $x \in A$ as $n \rightarrow \infty$, then there exists a subsequence $\left\{x_{n_{k}}\right\}$ of $\left\{x_{n}\right\}$ such that $\alpha\left(x_{n_{k}}, x\right) \geq 1$ for all $k$.

Theorem 14. Let $A$ and $B$ be nonempty closed subsets of $a$ complete metric space $X$ such that $A_{0}$ is nonempty and the pair $(A, B)$ has the P-property. Let $T: A \rightarrow B$ satisfy the following conditions:

(a) $T$ are $\alpha$-proximal admissible and generalized almost $(\varphi, \theta)_{\alpha}$-contraction;

(b) A satisfies condition $(H)$;

(c) there exist elements $x_{0}$ and $x_{1}$ in $A_{0}$ such that $d\left(x_{1}, T x_{0}\right)=d(A, B)$ and $\alpha\left(\left(x_{0}, x_{1}\right)\right) \geq 1$;

Then there exists an element $x \in A$ such that

$$
d(x, T x)=d(A, B) .
$$

Moreover, for any fixed $x_{0} \in A_{0}$, the sequence $\left\{x_{n}\right\}$, defined by

$$
d\left(x_{n+1}, T x_{n}\right)=d(A, B),
$$

converges to the element $x$.

Proof. As in the proof of Theorem 13, we have

$$
d\left(x_{n+1}, T x_{n}\right)=d(A, B)
$$

for all $n \geq 0$. Moreover, $\left\{x_{n}\right\}$ is a Cauchy sequence and converges to some point $x \in A$. By the $P$-property and (28), we have

$$
d\left(T x_{n-1}, T x_{n}\right)=d\left(x_{n}, x_{n+1}\right) \leq \varphi^{n}\left(d\left(x_{0}, x_{1}\right)\right)
$$

for all $n \in \mathbb{N} \cup\{0\}$. That is, $\lim _{n \rightarrow \infty} d\left(T x_{n-1}, T x_{n}\right)=0$ and, by the same argument as proof of Theorem 13, we obtain that $\left\{T x_{n}\right\}$ is a Cauchy sequence. Since $B$ is a closed subset of the complete metric space $(X, d)$, there exists $x_{\star} \in B$ such that $T x_{n}$ converges to $x_{\star}$. Therefore

$$
d\left(x, x_{\star}\right)=\lim _{n \rightarrow \infty} d\left(x_{n+1}, T x_{n}\right)=d(A, B) .
$$

On the other hand, from the condition $(H)$ of $T$, then there exists a subsequence $\left\{x_{n_{k}}\right\}$ of $\left\{x_{n}\right\}$ such that $\alpha\left(x_{n_{k}}, x\right) \geq 1$ for all $k$. The pair $(A, B)$ has $P$-property and property of mapping $T$; we get

$$
\begin{aligned}
& d\left(x_{n_{k}+1}, x\right) \\
& =d\left(T x_{n_{k}}, T x\right) \\
& \leq \alpha\left(x_{n_{k}}, x\right) d\left(T x_{n_{k}}, T x\right) \\
& \leq \quad \varphi\left(M\left(x_{n_{k}}, x\right)\right) \\
& \quad+\theta\left(d\left(x_{n_{k}}, T x\right)-d(A, B), d\left(x, T x_{n_{k}}\right)-d(A, B)\right. \\
& \left.\quad d(x, T x)-d(A, B), d\left(x_{n_{k}}, T x_{n_{k}}\right)-d(A, B)\right) .
\end{aligned}
$$

Indeed,

$$
\begin{aligned}
& M\left(x_{n_{k}}, x\right) \\
& =\max \left\{d\left(x_{n_{k}}, x\right), d\left(x_{n_{k}}, T x_{n_{k}}\right)-d(A, B), d(x, T x)\right. \\
& -d(A, B), \frac{1}{2}\left[d\left(x_{n_{k}}, T x\right)+d\left(x, T x_{n_{k}}\right)\right] \\
& -d(A, B)\} \\
& \leq \max \left\{d\left(x_{n_{k}}, x\right), d\left(x_{n_{k}}, x_{n_{k}+1}\right)+d\left(x_{n_{k}+1}, T x_{n_{k}}\right)\right. \\
& -d(A, B), d(x, T x)-d(A, B), \\
& \frac{1}{2}\left[d\left(x_{n_{k}}, x\right)+d(x, T x)+d\left(x, x_{n_{k}+1}\right)\right. \\
& \left.\left.+d\left(x_{n_{k}+1}, T x_{n_{k}}\right)\right]-d(A, B)\right\} \\
& \leq \max \left\{d\left(x_{n_{k}}, x\right), d\left(x_{n_{k}}, x_{n_{k}+1}\right), d(x, T x)-d(A, B),\right. \\
& \frac{1}{2}\left[d\left(x_{n_{k}}, x\right)+d(x, T x)+d\left(x, x_{n_{k}+1}\right)+d(A, B)\right] \\
& -d(A, B)\}:=\mathscr{M}\left(x_{n_{k}}, x\right) .
\end{aligned}
$$

From the definition of $\mathscr{M}\left(x_{n_{k}}, x\right)$, we get

$$
\lim _{k \rightarrow \infty} \mathscr{M}\left(x_{n_{k}}, x\right)=d(x, T x)-d(A, B) .
$$

Since

$$
\begin{aligned}
d(x, T x) & \leq d\left(x, x_{n_{k}+1}\right)+d\left(x_{n_{k}+1}, T x_{n_{k}}\right)+d\left(T x_{n_{k}}, T x\right) \\
& \leq d\left(x, x_{n_{k}+1}\right)+d(A, B)+d\left(T x_{n_{k}}, T x\right)
\end{aligned}
$$


it follows that

$$
\begin{aligned}
d(x, T x)-d\left(x, x_{n_{k}+1}\right)-d(A, B) & \\
\leq & d\left(T x_{n_{k}}, T x\right) \\
\leq & \alpha\left(x_{n_{k}}, x\right) d\left(T x_{n_{k}}, T x\right) \\
\leq & \varphi\left(M\left(x_{n_{k}}, x\right)\right) \\
& +\theta\left(d\left(x_{n_{k}}, T x\right)-d(A, B), d\left(x, T x_{n_{k}}\right)-d(A, B),\right. \\
& \left.\quad d(x, T x)-d(A, B), d\left(x_{n_{k}}, T x_{n_{k}}\right)-d(A, B)\right) \\
\leq & \varphi\left(\mathscr{M}\left(x_{n_{k}}, x\right)\right) \\
& +\theta\left(d\left(x_{n_{k}}, T x\right)-d(A, B), d\left(x, T x_{n_{k}}\right)-d(A, B),\right. \\
& \left.\quad d(x, T x)-d(A, B), d\left(x_{n_{k}}, T x_{n_{k}}\right)-d(A, B)\right) .
\end{aligned}
$$

Suppose that

$$
d(x, T x)-d(A, B)>0 .
$$

Then for $k$ large enough, we have $\mathscr{M}\left(x_{n_{k}}, x\right)>0$. Using the property $\varphi(t)<t$ for all $t>0$, we get

$$
\begin{aligned}
d(x, T x)-d\left(x, x_{n_{k}+1}\right)-d(A, B) & \\
< & \mathscr{M}\left(x_{n_{k}}, x\right) \\
+ & \theta\left(d\left(x_{n_{k}}, T x\right)-d(A, B), d\left(x, T x_{n_{k}}\right)-d(A, B),\right. \\
& \left.d(x, T x)-d(A, B), d\left(x_{n_{k}}, T x_{n_{k}}\right)-d(A, B)\right) .
\end{aligned}
$$

Combining (37) and (40) with (44) and the property of $\theta$, we obtain that

$$
\begin{aligned}
& d(x, T x)-d(A, B) \\
& =\lim _{k \rightarrow \infty} d(x, T x)-d\left(x, x_{n_{k}+1}\right)-d(A, B) \\
& <\lim _{k \rightarrow \infty} M\left(x_{n_{k}}, x\right) \\
& \quad+\lim _{k \rightarrow \infty} \theta\left(d\left(x_{n_{k}}, T x\right)-d(A, B), d\left(x, T x_{n_{k}}\right)-d(A, B),\right. \\
& =\lim _{k \rightarrow \infty} M\left(x_{n_{k}}, x\right) \\
& =d(x, T x)-d(A, B)
\end{aligned}
$$

which is a contradiction and thus $d(x, T x)-d(A, B)=0$. Hence, $d(x, T x)=d(A, B)$ and the proof is complete.
3.2. The Uniqueness. Next, we present an example where it can be appreciated that hypotheses in Theorems 13 and 14 do not guarantee uniqueness of the best proximity point.

Example 15. Let $X=R^{2}$ with the Euclidean metric. Consider $A:=\{(2,0),(0,2)\}$ and $B:=\{(-2,0),(0,-2)\}$. Obviously, $(A, B)$ satisfies the $P$-property and $d(A, B)=2 \sqrt{2}$; furthermore $A_{0}=A$ and $B_{0}=B$. Define $T: A \rightarrow B$ by $T(x, y)=(-y / 2,-x / 2)$ for all $x, y \in A$; clearly $T$ is continuous. Let $\alpha: A \times A \rightarrow[0, \infty)$ be defined by

$$
\alpha(x, y)= \begin{cases}2 ; & x=y, \\ \frac{1}{2} ; & x \neq y .\end{cases}
$$

We can show that $T$ are $\alpha$-proximal admissible and generalized almost $(\varphi, \theta)_{\alpha}$-contraction with $\varphi(t)=t / 2$ for all $t \geq 0$ and for all $\theta \in \Theta$. Furthermore,

$$
\begin{aligned}
d((2,0), T(2,0)) & =d((2,0),(0,-2))=d((0,2),(-2,0)) \\
& =d((0,2), T(0,2))=d(A, B)=2 \sqrt{2}
\end{aligned}
$$

Therefore, $(2,0)$ and $(0,2)$ are a best proximity point of mapping $T$.

Now, we need a sufficient condition to give uniqueness of the best proximity point as follows.

Definition 16 (see [17]). Let $T: A \rightarrow B$ be a non-selfmapping and $\alpha: A \times A \rightarrow[0, \infty)$. One says that $T$ is $(\alpha, d)$-regular if, for all $(x, y) \in \alpha^{-1}([0,1))$, there exists $z \in$ $A_{0}$ such that

$$
\alpha(x, z) \geq 1, \quad \alpha(y, z) \geq 1 .
$$

Theorem 17. Adding condition $(\alpha, d)$-regular of $T$ to the hypotheses of Theorem 13, then one obtains the uniqueness of the best proximity point of $T$.

Proof. We will only prove the part of uniqueness. Suppose that there exist $x$ and $x^{*}$ in $A$ which are distinct best proximity points; that is,

$$
d(x, T x)=d(A, B), \quad d\left(x^{*}, T x^{*}\right)=d(A, B) .
$$

Using the pair $(A, B)$ that has $P$-property, we have

$$
d\left(x, x^{*}\right)=d\left(T x, T x^{*}\right) .
$$


Case 1 (if $\alpha\left(x, x^{*}\right) \geq 1$ ). By (50) and generalized almost $(\varphi, \theta)_{\alpha}$-contraction of $T$, we have

$$
\begin{aligned}
d\left(x, x^{*}\right) & \\
= & d\left(T x, T x^{*}\right) \\
\leq & \alpha\left(x, x^{*}\right) d\left(T x, T x^{*}\right) \\
\leq & \varphi\left(M\left(x, x^{*}\right)\right) \\
& +\theta\left(d\left(x^{*}, T x\right)-d(A, B), d\left(x, T x^{*}\right)-d(A, B),\right. \\
& \left.\quad d(x, T x)-d(A, B), d\left(x^{*}, T x^{*}\right)-d(A, B)\right) \\
= & \varphi\left(M\left(x, x^{*}\right)\right) \\
& +\theta\left(d\left(x^{*}, T x\right)-d(A, B), d\left(x, T x^{*}\right)-d(A, B), 0,0\right) \\
= & \varphi\left(M\left(x, x^{*}\right)\right)
\end{aligned}
$$

since

$$
\begin{aligned}
& M\left(x, x^{*}\right) \\
&=\max \left\{d\left(x, x^{*}\right), d(x, T x)-d(A, B), d\left(x^{*}, T x^{*}\right)\right. \\
&\left.-d(A, B), \frac{1}{2}\left[d\left(x, T x^{*}\right)+d\left(x^{*}, T x\right)\right]-d(A, B)\right\} \\
&=\max \left\{d\left(x, x^{*}\right), 0,0, \frac{1}{2}\left[d\left(x, T x^{*}\right)+d\left(x^{*}, T x\right)\right]\right. \\
&--d(A, B)\} \\
& \leq \max \left\{d\left(x, x^{*}\right), \frac{1}{2}\left[d\left(x, x^{*}\right)+d\left(x^{*}, T x^{*}\right)+d\left(x^{*}, x\right)\right.\right. \\
&+d(x, T x)]-d(A, B)\} \\
&=\max \left\{d\left(x, x^{*}\right), \frac{1}{2}\left[d\left(x, x^{*}\right)+d\left(x^{*}, x\right)\right]\right\} \\
&=d\left(x, x^{*}\right) .
\end{aligned}
$$

Combining (51) with (52) and using the property $\varphi(t)<t$ for all $t>0$, we get

$$
d\left(x, x^{*}\right) \leq \varphi\left(M\left(x, x^{*}\right)\right)=\varphi\left(d\left(x, x^{*}\right)\right)<d\left(x, x^{*}\right)
$$

which is a contradiction and hence $x=x^{*}$.

Case 2 (if $\alpha\left(x, x^{*}\right)<1$ ). By the $(\alpha, d)$-regular of $T$, there exists $z \in A_{0}$ such that

$$
\alpha((x, z)) \geq 1, \quad \alpha\left(x^{*}, z\right) \geq 1 .
$$

Since $T\left(A_{0}\right) \subseteq B_{0}$, there exists a point $v_{0} \in A_{0}$ such that

$$
d\left(v_{0}, T z\right)=d(A, B)
$$

From $\alpha(x, z) \geq 1, d(x, T x)=d(A, B)$, and $d\left(v_{0}, T z\right)=$ $d(A, B)$ and by the $\alpha$-proximal admissible, we have

$$
\alpha\left(x, v_{0}\right) \geq 1 .
$$

Since $T\left(A_{0}\right) \subseteq B_{0}$, there exists a point $v_{1} \in A_{0}$ such that

$$
d\left(v_{1}, T v_{0}\right)=d(A, B) .
$$

By similar argument as above, we can conclude that $\alpha\left(x, v_{1}\right) \geq$ 1 . One can proceed further in a similar fashion to find $v_{n}$ in $A_{0}$ with $v_{n+1} \in A_{0}$ such that

$$
d\left(v_{n+1}, T v_{n}\right)=d(A, B), \quad \alpha\left(x, v_{n}\right) \geq 1,
$$

for all $n \in \mathbb{N}$. By (58), the pair $(A, B)$ has $P$-property and property of mapping $T$; we get

$$
d\left(x, v_{n+1}\right)=d\left(T x, T v_{n}\right) .
$$

Using the property of mapping $T$, we get

$$
\begin{aligned}
d\left(x, v_{n+1}\right) & \\
= & d\left(T x, T v_{n}\right) \\
\leq & \alpha\left(x, v_{n}\right) d\left(T x, T v_{n}\right) \\
\leq & \varphi\left(M\left(x, v_{n}\right)\right) \\
& +\theta\left(d\left(v_{n}, T x\right)-d(A, B), d\left(x, T v_{n}\right)-d(A, B),\right. \\
& \left.\quad d(x, T x)-d(A, B), d\left(v_{n}, T v_{n}\right)-d(A, B)\right) \\
= & \varphi\left(M\left(x, v_{n}\right)\right) \\
& +\theta\left(d\left(v_{n}, T x\right)-d(A, B), d\left(x, T v_{n}\right)-d(A, B),\right. \\
\quad & \left.\quad 0, d\left(v_{n}, T v_{n}\right)-d(A, B)\right) \\
= & \varphi\left(M\left(x, v_{n}\right)\right)
\end{aligned}
$$

since

$$
\begin{aligned}
M\left(x, v_{n}\right) & \\
=\max & \left\{d\left(x, v_{n}\right), d(x, T x)-d(A, B), d\left(v_{n}, T v_{n}\right)\right. \\
& \left.-d(A, B), \frac{1}{2}\left[d\left(x, T v_{n}\right)+d\left(v_{n}, T x\right)\right]-d(A, B)\right\} \\
=\max & \left\{d\left(x, v_{n}\right), 0,0, \frac{1}{2}\left[d\left(x, T v_{n}\right)+d\left(v_{n}, T x\right)\right]\right. \\
\leq & \max \left\{d\left(x, v_{n}\right), \frac{1}{2}\left[d\left(x, v_{n+1}\right)+d\left(v_{n+1}, T v_{n}\right)\right\}\right. \\
= & \max \left\{d\left(x, v_{n}\right), \frac{1}{2}\left[d\left(x, v_{n+1}\right)+d\left(v_{n}, x\right)\right]\right\} \\
\leq & \max \left\{d\left(x, v_{n}\right), d\left(x, v_{n+1}\right)\right\} .
\end{aligned}
$$


Thus

$$
\begin{aligned}
d\left(x, v_{n+1}\right) & \leq \varphi\left(M\left(x, v_{n}\right)\right) \\
& \leq \varphi\left(\max \left\{d\left(x, v_{n}\right), d\left(x, v_{n+1}\right)\right\}\right)
\end{aligned}
$$

If $v_{N}=x$, for some $N \in \mathbb{N}$. By (59), we get

$$
d\left(x, v_{N+1}\right)=d\left(T x, T v_{N}\right)=0
$$

which implies that $v_{N+1}=x$. Moreover, we obtain $v_{n}=x$ for all $n \geq N$ and thus $v_{n} \rightarrow x$ as $n \rightarrow \infty$. Suppose that $v_{n} \neq x$ for all $n \in \mathbb{N}$; then $d\left(v_{n}, x\right)>0$ for all $n$. If $\max \left\{d\left(x, v_{n}\right), d\left(x, v_{n+1}\right)\right\}=d\left(x, v_{n+1}\right)$, by the property $\varphi(t)<$ $t$ for all $t>0$, we get

$$
\begin{aligned}
d\left(x, v_{n+1}\right) & \leq \varphi\left(M\left(x, v_{n}\right)\right) \\
& =\varphi\left(d\left(x, v_{n+1}\right)\right)<d\left(x, v_{n+1}\right)
\end{aligned}
$$

which is a contradiction and hence $\max \left\{d\left(x, v_{n}\right), d\left(x, v_{n+1}\right)\right\}$ $=d\left(x, v_{n}\right)$. That is,

$$
d\left(x, v_{n+1}\right) \leq \varphi\left(M\left(x, v_{n}\right)\right)=\varphi\left(d\left(x, v_{n}\right)\right)
$$

for all $n \geq N$. By induction of (65), we have

$$
d\left(x, v_{n+1}\right) \leq \varphi^{n}\left(d\left(x, v_{1}\right)\right) .
$$

Taking $n \rightarrow \infty$, we obtain that $v_{n} \rightarrow x$ as $n \rightarrow \infty$. So, in all cases, we have $v_{n} \rightarrow x$ as $n \rightarrow \infty$. Similarly, we can prove that $v_{n} \rightarrow x^{*}$ as $n \rightarrow \infty$. By the uniqueness of limit, we conclude that $x=x^{*}$ and this completes the proof.

Theorem 18. Adding condition $(\alpha, d)$-regular of $T$ to the hypotheses of Theorem 14, then we obtain the uniqueness of the best proximity point of $T$.

Proof. Combine the proofs of Theorems 17 and 14.

\section{Consequences}

4.1. Best Proximity Points Theorems. If we take $\varphi(t)=k t$, where $0 \leq k<1$ and $\theta\left(t_{1}, t_{2}, t_{3}, t_{4}\right)=L \min \left\{t_{1}, t_{2}, t_{3}, t_{4}\right\}$, then Theorem 13 and Theorem 14, we get the following.

Theorem 19. Let $A$ and $B$ be nonempty closed subsets of $a$ complete metric space $X$ such that $A_{0}$ is nonempty and the pair $(A, B)$ has the P-property. Let $T: A \rightarrow B$ satisfy the following conditions:

(a) $T$ is $\alpha$-proximal admissible and

$$
\begin{aligned}
& \alpha(x, y) d(T x, T y) \\
& \leq k M(x, y) \\
& +L \min \{d(x, T y)-d(A, B), d(y, T x)-d(A, B) \\
& \quad, d(x, T x)-d(A, B), d(y, T y)-d(A, B)\}
\end{aligned}
$$

for all $x, y \in A$; (b) $T$ is continuous (or A satisfies condition $(H)$ );

(c) there exist elements $x_{0}$ and $x_{1}$ in $A_{0}$ such that $d\left(x_{1}, T x_{0}\right)=d(A, B)$ and $\alpha\left(\left(x_{0}, x_{1}\right)\right) \geq 1 ;$

(d) $T\left(A_{0}\right) \subseteq B_{0}$.

Then there exists an element $x \in A$ such that

$$
d(x, T x)=d(A, B) .
$$

Moreover, for any fixed $x_{0} \in A_{0}$, the sequence $\left\{x_{n}\right\}$, defined by

$$
d\left(x_{n+1}, T x_{n}\right)=d(A, B),
$$

converges to the element $x$.

If we add the condition that $T$ is $(\alpha, d)$-regular in Theorem 19, therefore we can obtain the uniqueness of the best proximity point.

If we take $\alpha(x, y)=1$, for all $x, y \in A$ in Theorems 13 and 14, we get the following Theorems.

Theorem 20. Let $A$ and $B$ be nonempty closed subsets of $a$ complete metric space $X$ such that $A_{0}$ is nonempty and the pair $(A, B)$ has the $P$-property. Let $T: A \rightarrow B$ satisfy the following conditions:

(a)

$$
\begin{aligned}
& d(T x, T y) \\
& \leq \varphi(M(x, y))+\theta(d(x, T y)-d(A, B), d(y, T x) \\
& -d(A, B) d(x, T x) \\
& -d(A, B), d(y, T y)-d(A, B))
\end{aligned}
$$

for all $x, y \in A$;

(b) $T$ is continuous (or A satisfies condition $(H)$ );

(c) $T\left(A_{0}\right) \subseteq B_{0}$

Then there exists an element $x \in A$ such that

$$
d(x, T x)=d(A, B) .
$$

Moreover, for any fixed $x_{0} \in A_{0}$, the sequence $\left\{x_{n}\right\}$, defined by

$$
d\left(x_{n+1}, T x_{n}\right)=d(A, B),
$$

converges to the element $x$.

If $M(x, y)=d(x, y)$, then Theorem 20 includes the following.

Theorem 21. Let $A$ and $B$ be nonempty closed subsets of $a$ complete metric space $X$ such that $A_{0}$ is nonempty and the pair $(A, B)$ has the P-property. Let $T: A \rightarrow B$ satisfy the following conditions: 
(a)

$$
\begin{aligned}
& d(T x, T y) \\
& \leq \varphi(d(x, y))+\theta(d(x, T y)-d(A, B), d(y, T x) \\
& -d(A, B) d(x, T x) \\
& -d(A, B), d(y, T y)-d(A, B))
\end{aligned}
$$

for all $x, y \in A$;

(b) $T$ is continuous (or A satisfies condition $(H)$ );

(c) $T\left(A_{0}\right) \subseteq B_{0}$.

Then there exists an element $x \in A$ such that

$$
d(x, T x)=d(A, B) .
$$

Moreover, for any fixed $x_{0} \in A_{0}$, the sequence $\left\{x_{n}\right\}$, defined by

$$
d\left(x_{n+1}, T x_{n}\right)=d(A, B),
$$

converges to the element $x$.

If we take $\varphi(t)=k t$ and $\theta\left(t_{1}, t_{2}, t_{3}, t_{4}\right)=L$ min $\left\{t_{1}, t_{2}, t_{3}, t_{4}\right\}$, for all $x, y \in A$ in Theorem 21 , we obtain the following theorem.

Theorem 22. Let $A$ and $B$ be nonempty closed subsets of $a$ complete metric space $X$ such that $A_{0}$ is nonempty and the pair $(A, B)$ has the P-property. Let $T: A \rightarrow B$ satisfy the following conditions:

(a)

$$
\begin{aligned}
& d(T x, T y) \\
& \leq k M(x, y) \\
& +L \min \{d(x, T y)-d(A, B), d(y, T x)-d(A, B) \\
& , d(x, T x)-d(A, B), d(y, T y)-d(A, B)\}
\end{aligned}
$$

for all $x, y \in A$;

(b) $T$ is continuous (or A satisfies condition $(H)$ );

(c) $T\left(A_{0}\right) \subseteq B_{0}$.

Then there exists an element $x \in A$ such that

$$
d(x, T x)=d(A, B) .
$$

Moreover, for any fixed $x_{0} \in A_{0}$, the sequence $\left\{x_{n}\right\}$, defined by

$$
d\left(x_{n+1}, T x_{n}\right)=d(A, B),
$$

converges to the element $x$.

If $M(x, y)=d(x, y)$ and putting $L=0$ in Theorem 22, we obtain the following.
Theorem 23. Let $A$ and $B$ be nonempty closed subsets of $a$ complete metric space $X$ such that $A_{0}$ is nonempty and the pair $(A, B)$ has the P-property. Let $T: A \rightarrow B$ satisfy the following conditions:

(a)

$$
d(T x, T y) \leq k d(x, y)
$$

for all $x, y \in A$;

(b) $T$ is continuous (or A satisfies condition $(H)$ );

(c) there exist elements $x_{0}$ and $x_{1}$ in $A_{0}$ such that $d\left(x_{1}, T x_{0}\right)=d(A, B)$

(d) $T\left(A_{0}\right) \subseteq B_{0}$.

Then there exists an element $x \in A$ such that

$$
d(x, T x)=d(A, B) .
$$

Moreover, for any fixed $x_{0} \in A_{0}$, the sequence $\left\{x_{n}\right\}$, defined by

$$
d\left(x_{n+1}, T x_{n}\right)=d(A, B),
$$

converges to the element $x$.

If $M(x, y)=(k / 2)[d(x, T y)+d(y, T x)]-d(A, B)$ and putting $L=0$ in Theorem 22, we obtain the following theorem.

Theorem 24. Let $A$ and $B$ be nonempty closed subsets of $a$ complete metric space $X$ such that $A_{0}$ is nonempty and the pair $(A, B)$ has the $P$-property. Let $T: A \rightarrow B$ satisfy the following conditions:

(a)

$$
d(T x, T y) \leq \frac{k}{2}[d(x, T y)+d(y, T x)]-d(A, B)
$$

$$
\text { for all } x, y \in A \text {; }
$$

(b) $T$ is continuous (or A satisfies condition $(H)$ );

(c) there exist elements $x_{0}$ and $x_{1}$ in $A_{0}$ such that $d\left(x_{1}, T x_{0}\right)=d(A, B)$

(d) $T\left(A_{0}\right) \subseteq B_{0}$.

Then there exists an element $x \in A$ such that

$$
d(x, T x)=d(A, B) .
$$

Moreover, for any fixed $x_{0} \in A_{0}$, the sequence $\left\{x_{n}\right\}$, defined by

$$
d\left(x_{n+1}, T x_{n}\right)=d(A, B),
$$

converges to the element $x$. 
4.2. Fixed Points Theorem. It is easy to observe that, for selfmappings, our results include the following.

Theorem 25. Let A be nonempty closed subsets of a complete metric space $X$ and $T: A \rightarrow A$ such that

$$
\begin{aligned}
d(T x, T y) & \\
\leq & \varphi(M(x, y)) \\
& +\theta(\{d(x, T y), d(y, T x), d(x, T x), d(y, T y)\}),
\end{aligned}
$$

for all $x, y \in A$, where $\varphi \in \Psi \theta \in \Theta$. Then T has a unique fixed point $x \in A$. Moreover, for any fixed $x_{0} \in A$, the sequence $\left\{x_{n}\right\}$, defined by $x_{n+1}=T x_{n}$, converges to the element $x$.

Theorem 26. Let $A$ be nonempty closed subsets of a complete metric space $X$ and $T: A \rightarrow A$ such that

$$
\begin{aligned}
& d(T x, T y) \\
& \leq k M(x, y) \\
& \quad+L \min \{d(x, T y), d(y, T x), d(x, T x), d(y, T y)\} .
\end{aligned}
$$

Then $T$ has a unique fixed point $x \in A$. Moreover, for any fixed $x_{0} \in A$, the sequence $\left\{x_{n}\right\}$, defined by $x_{n+1}=T x_{n}$, converges to the element $x$.

Theorem 27. Let $A$ be nonempty closed subsets of a complete metric space $X$ and $T: A \rightarrow A$ such that

$$
\begin{aligned}
& d(T x, T y) \\
& \leq k d(x, y) \\
& \quad+L \min \{d(x, T y), d(y, T x), d(x, T x), d(y, T y)\}
\end{aligned}
$$

for all $x, y \in A$. Then $T$ has a unique fixed point $x \in A$. Moreover, for any fixed $x_{0} \in A$, the sequence $\left\{x_{n}\right\}$, defined by $x_{n+1}=T x_{n}$, converges to the element $x$.

\section{Some Applications and an Example}

We recall some preliminaries from (see, $[6,17]$ also) as follows.

Let $(X, d)$ be a metric space and $\mathscr{R}$ a binary relation over $X$. Denote

$$
\mathcal{S}=\mathscr{R} \cup \mathscr{R}^{-1} ;
$$

this is the symmetric relation attached to $\mathscr{R}$. Clearly,

$$
x, y \in X, \quad x \mathcal{S} y \Longleftrightarrow x \mathscr{R} y \text { or } y \mathscr{R} x .
$$

Definition 28 (see [17]). A mapping $T: A \rightarrow B$ is said to be proximal comparative if and only if

$$
\left\{\begin{array}{l}
x_{1} \delta x_{2} \\
d\left(u_{1}, T x_{1}\right)=d(A, B) \\
d\left(u_{2}, T x_{2}\right)=d(A, B)
\end{array} \Longrightarrow u_{1} \delta u_{2} .\right.
$$

Corollary 29. Let $(X, d)$ be a complete metric space, $\mathscr{R}$ a binary relation over $X$, and $A$ and $B$ two nonempty, closed subsets of $X$ such that $A_{0}$ are nonempty and the pair $(A, B)$ has the P-property. Let $T: A \rightarrow B$ such that the following conditions hold:

(a) $T$ is a continuous proximal comparative mapping;

(b) there exist elements $x_{0}$ and $x_{1}$ in $A_{0}$ such that $d\left(x_{1}, T x_{0}\right)=d(A, B)$ and $x_{0} \delta x_{1} ;$

(c) there exist $\varphi \in \Psi$ and $\theta \in \Theta$ such that $x, y \in A, x \mathcal{S} y$ implies that

$$
\begin{aligned}
& d(T x, T y) \\
& \leq \varphi(M(x, y)) \\
& +\theta(d(y, T x)-d(A, B), d(x, T y)-d(A, B), \\
& \quad d(x, T x)-d(A, B), d(y, T y)-d(A, B))
\end{aligned}
$$

(d) $T\left(A_{0}\right) \subseteq B_{0}$.

Then there exists an element $x \in A$ such that

$$
d(x, T x)=d(A, B) .
$$

Proof. Define the mapping $\alpha: A \times A \rightarrow[0, \infty)$ by

$$
\alpha(x, y)= \begin{cases}1 ; & x \mathcal{S} y \\ 0 ; & \text { otherwise. }\end{cases}
$$

Since $T$ is proximal comparative, we have

$$
\left\{\begin{array}{l}
x_{1} \delta x_{2} \\
d\left(u_{1}, T x_{1}\right)=d(A, B) \\
d\left(u_{2}, T x_{2}\right)=d(A, B)
\end{array} \Longrightarrow u_{1} \delta u_{2} .\right.
$$

for all $u, v, x, y \in A$. Using the definition of $\alpha$, we get

$$
\left\{\begin{array}{l}
\alpha(x, y) \geq 1 \\
d(u, T x)=d(A, B), \Longrightarrow \alpha(u, v) \geq 1 \\
d(v, T y)=d(A, B)
\end{array}\right.
$$

for all $u, v, x, y \in A$ and hence $T$ is $\alpha$-proximal admissible. Condition $(b)$ implies that $d\left(x_{1}, T x_{0}\right)=d(A, B)$ and $\alpha\left(x_{0}, x_{1}\right) \geq 1$. By condition (c), we get

$$
\begin{aligned}
\alpha(x, y) d(T x, T y) & \\
\leq & \varphi(M(x, y)) \\
+ & \theta(d(y, T x)-d(A, B), d(x, T y)-d(A, B), \\
& \quad d(x, T x)-d(A, B), d(y, T y)-d(A, B)) ;
\end{aligned}
$$

that is, $T$ is generalized almost $(\varphi, \theta)_{\alpha}$-contraction. Therefore, all hypotheses of Theorem 13 are satisfied, and the desired result follows immediately.

Next, below we give an example to illustrate the main result of Theorem 13. 
Example 30. Consider $X=R^{4}$ with the metric defined by

$$
\begin{aligned}
& d\left(\left(x_{1}, x_{2}, x_{3}, x_{4}\right),\left(y_{1}, y_{2}, y_{3}, y_{4}\right)\right) \\
& \quad=\left|x_{1}-y_{1}\right|+\left|x_{2}-y_{2}\right|+\left|x_{3}-y_{3}\right|+\left|x_{4}-y_{4}\right|
\end{aligned}
$$

for all $\left(x_{1}, x_{2}, x_{3}, x_{4}\right),\left(y_{1}, y_{2}, y_{3}, y_{4}\right) \in R^{4}$. Let $A, B \subset X$ defined by

$$
\begin{gathered}
A:=\left\{\left(0,0, \frac{1}{n}, \frac{-1}{n}\right)\right\} \cup\{(0,0,0,0)\}, \\
B:=\left\{\left(1,-1, \frac{1}{n}, \frac{-1}{n}\right)\right\} \cup\{(1,-1,0,0)\} .
\end{gathered}
$$

Then $A$ and $B$ are nonempty closed subsets of $X$ and $d(A, B)=$ 2. Moreover $A_{0}=A$ and $B_{0}=B$. Suppose

$$
\begin{aligned}
& d\left(\left(0,0, x_{1}, x_{2}\right),\left(1,-1, y_{1}, y_{2}\right)\right)=d(A, B)=2, \\
& d\left(\left(0,0, x_{1}^{\prime}, x_{2}^{\prime}\right),\left(1,-1, y_{1}^{\prime}, y_{2}^{\prime}\right)\right)=d(A, B)=2 ;
\end{aligned}
$$

then we get $x_{1}=y_{1}, x_{2}=y_{2}$ and $x_{1}^{\prime}=y_{1}^{\prime}, x_{2}^{\prime}=y_{2}^{\prime}$. Hence, the pair $(A, B)$ has the $P$-property. Let $T: A \rightarrow B$ be a mapping defined as

$$
T(0,0, x, y)=\left(0,0, \frac{x}{2}, \frac{y}{2}\right)
$$

for all $(0,0, x, y) \in A$. We define the mapping $\alpha: A \times A \rightarrow$ $[0, \infty)$ by

$$
\alpha(x, y)=1 \quad \forall x, y \in A .
$$

We can see that $T$ is generalized almost $(\varphi, \theta)_{\alpha}$-contraction with $\varphi \in \Psi$ given by $\varphi(t)=t / 2$ for all $t \geq 0$ and for all $\theta \in$ $\Theta$. Furthermore, $(0,0,0,0) \in A$ is a best proximity point of mapping $T$.

\section{Conclusions}

We introduce the new class of generalized almost $(\varphi, \theta)_{\alpha}$ contraction and presented sufficient conditions for proving the existence and uniqueness of the best proximity point. Moreover, we also gave some applications and examples to support our results.

\section{Conflict of Interests}

The authors declare that there is no conflict of interests regarding the publication of this paper.

\section{Acknowledgments}

The authors thank the referee for comments and suggestions on this paper. The third author was supported by the Commission on Higher Education, the Thailand Research Fund, and the King Mongkuts University of Technology Thonburi (Grant no. MRG550085).

\section{References}

[1] K. Fan, "Extensions of two fixed point theorems of F. E. Browder," Mathematische Zeitschrift, vol. 112, pp. 234-240, 1969.

[2] J. B. Prolla, "Fixed-point theorems for set-valued mappings and existence of best approximants," Numerical Functional Analysis and Optimization, vol. 5, no. 4, pp. 449-455, 1982-1983.

[3] S. Reich, "Approximate selections, best approximations, fixed points, and invariant sets," Journal of Mathematical Analysis and Applications, vol. 62, no. 1, pp. 104-113, 1978.

[4] V. M. Sehgal and S. P. Singh, "A generalization to multifunctions of Fan's best approximation theorem," Proceedings of the American Mathematical Society, vol. 102, no. 3, pp. 534-537, 1988.

[5] V. M. Sehgal and S. P. Singh, "A theorem on best approximations," Numerical Functional Analysis and Optimization, vol. 10, no. 1-2, pp. 181-184, 1989.

[6] M. Jleli and B. Samet, "Best proximity points for $\alpha-\psi$-proximal contractive type mappings and applications," Bulletin des Sciences Mathématiques, vol. 137, no. 8, pp. 977-995, 2013.

[7] W. Sintunavarat and P. Kumam, "The existence theorems of an optimal approximate solution for generalized proximal contraction mappings," Abstract and Applied Analysis, vol. 2013, Article ID 375604, 8 pages, 2013.

[8] C. Mongkolkeha and P. Kumam, "Best proximity point theorems for generalized cyclic contractions in ordered metric spaces," Journal of Optimization Theory and Applications, vol. 155, no. 1, pp. 215-226, 2012.

[9] C. Mongkolkeha and P. Kumam, "Some common best proximity points for proximity commuting mappings," Optimization Letters, vol. 7, no. 8, pp. 1825-1836, 2013.

[10] W. Sintunavarat and P. Kumam, "Coupled best proximity point theorem in metric spaces," Fixed Point Theory and Applications, vol. 2012, p. 93, 2012.

[11] S. Karpagam and S. Agrawal, "Best proximity point theorems for $p$-cyclic Meir-Keeler contractions," Fixed Point Theory and Applications, vol. 2009, Article ID 197308, 9 pages, 2009.

[12] S. Sadiq Basha, P. Veeramani, and D. V. Pai, "Best proximity pair theorems," Indian Journal of Pure and Applied Mathematics, vol. 32, no. 8, pp. 1237-1246, 2001.

[13] V.S. Raj, "A best proximity point theorem for weakly contractive non-self-mappings," Nonlinear Analysis: Theory, Methods \& Applications, vol. 74, no. 14, pp. 4804-4808, 2011.

[14] A. Abkar and M. Gabeleh, "A best proximity point theorem for Suzuki type contraction, non-self-mappings," Fixed Point Theory, vol. 14, no. 2, pp. 281-288, 2013.

[15] V. Sankar Raj, "Best proximity point theorems for non-self mappings," Fixed Point Theory, vol. 14, no. 2, pp. 447-454, 2013.

[16] B. Samet, "Some results on best proximity points," Journal of Optimization Theory and Applications, vol. 159, no. 1, pp. 281291, 2013.

[17] M. Jleli, E. Karapinar, and B. Samet, "Best, proximity points forgeneralized $\alpha$ - $\psi$-proximal contractive typemappings," Journal of Applied Mathematics. In press.

[18] B. Samet, C. Vetro, and P. Vetro, "Fixed point theorems for $\alpha \psi$-contractive type mappings," Nonlinear Analysis: Theory, Methods and Applications, vol. 75, no. 4, pp. 2154-2165, 2012.

[19] S. Sadiq Basha and P. Veeramani, "Best proximity pair theorems for multifunctions with open fibres," Journal of Approximation Theory, vol. 103, no. 1, pp. 119-129, 2000.

[20] A. Abkar and M. Gabeleh, "Global optimal solutions of noncyclic mappings in metric spaces," Journal of Optimization Theory and Applications, vol. 153, no. 2, pp. 298-305, 2012. 


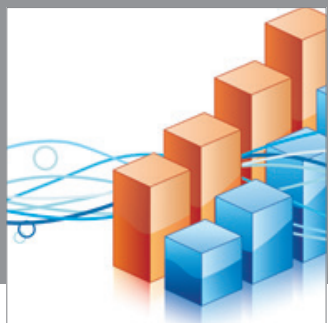

Advances in

Operations Research

mansans

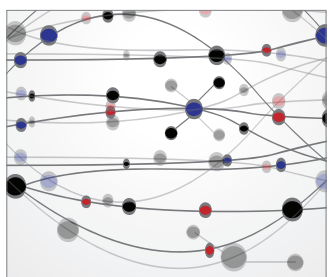

The Scientific World Journal
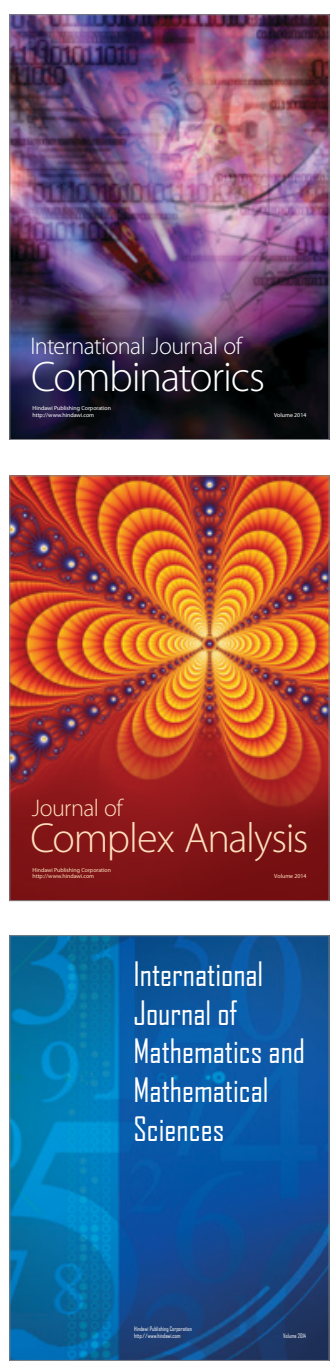
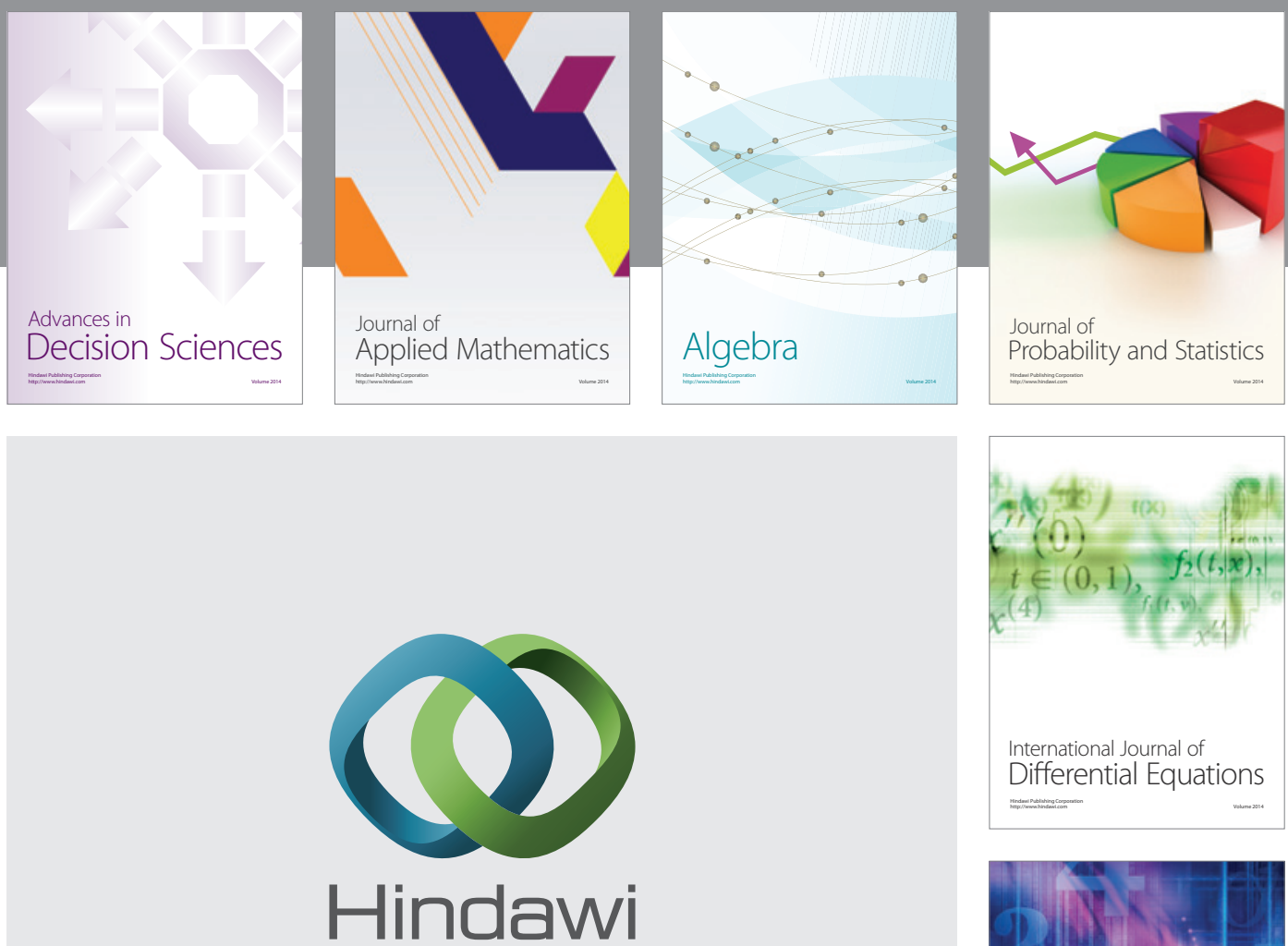

Submit your manuscripts at http://www.hindawi.com
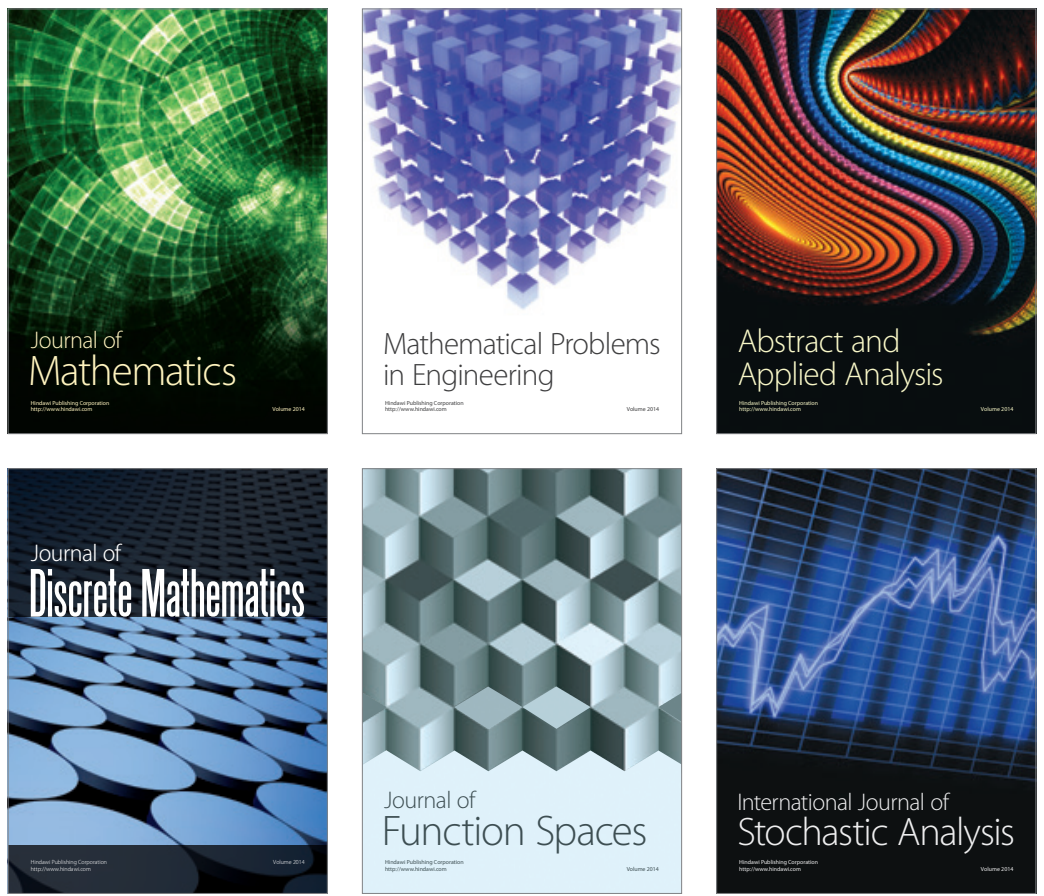

Journal of

Function Spaces

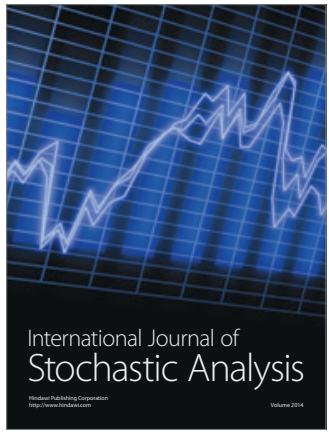

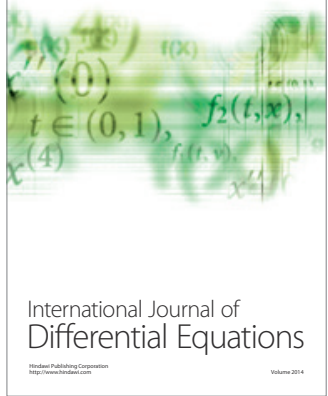
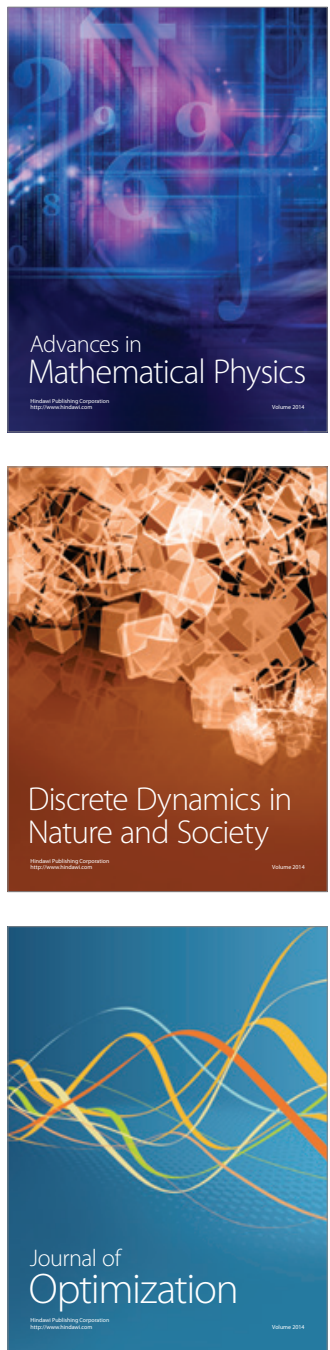